\title{
PENTAS SENI TAYUB SEBAGAI RITUAL UNTUK MENDATANGKAN KEMAKMURAN
}

\author{
Purwadi \\ Universitas Negeri Yogyakarta \\ purwadi@uny.ac.id
}

\begin{abstract}
ABSTRAK
Artikel ini akan menjelaskan tentang seni Tayub di Kabupaten Nganjuk. Tayub adalah seni tari yang dilakukan oleh waranggana dan panjak. Seni tari ini bertujuan untuk apresiasi kepada Dewi Sri. Masyarakat Nganjuk percaya bahwa Dewi Sri dapat memberi kesejahteraan kepada petani. Setiap musim tanam, petani membutuhkan perlindungan spiritual dari Dewi Sri. Program tani ini direalisasikan dengan tayub art show. Menurut orang Nganjuk seni tayub mengandung tentang moralitas, spiritualitas dan kemanusiaan.
\end{abstract}

Kata kunci: tayub, seni, Dewi Sri

\begin{abstract}
This article will describe about Tayub art in Nganjuk district. Tayub is a dance art that done by waranggana and panjak. This dance art have purpose to apreciate to Dewi Sri. Nganjuk community believe that Dewi Sri can give welfare to peasant. Every planting season, peasant need spiritual protection from Dewi Sri. This peasant program realized with tayub art show. According to Nganjuk people tayub art contain about morality, spirituality and humanity.

Keywords: tayub, art, Dewi Sri
\end{abstract}

\section{PENDAHULUAN}

Kesenian amat diperlukan kehadirannya oleh segenap masyarakat untuk memperhalus perasaan. Seni tayub di kabupaten Nganjuk hingga saat ini tetap berkembang dan digemari oleh masyarakat. Tayub mempunyai pengertian ditata supaya guyub. Perasaan untuk menikmati keindahan betul-betul dirasakan, agar tampak kompak, bersatu, manunggal dalam kebersamaan. Kenyataannya memang seni tayub bisa membuat semangat kebersamaan di kalangan masyarakat.

Pelaksanaan seni tayub memerlukan persiapan yang matang. Sebulan sebelum seni langen tayub dipentaskan, undangan, serat ulem, informasi, pengumuman dan wara-wara sudah menyebar ke segala penjuru. Hari yang berbahagia itu dinanti oleh keluarga yang punya hajad, saudara, handai taulan, tetangga, pandhemen serta para bakul palen. Hidup dalam bentuknya yang lebih terkonsentrasi menjadi perilaku yang utama (Peter Brook, 2002: 59). Tayub menjadi inspirasi bagi masyarakat pendukungnya.

Segenap daya upaya dikerahkan demi suksesnya pementasan seni langen tayub. Punya hajad mantu bagi keluarga petani di Nganjuk akan merasa terhormat bila nanggap penggambyong. Surat ulem bagi para undangan dicantumkan hiburan langen tayub. Gengsi keluarga bertambah mewah. Nama keluarga menjadi terkenal, harum dan banyak disanjung. Sejak semula keluarga itu akan memeriahkan pesta mantu dengan hiburan langen tayub. Ditanggung pasti mewah, 
semarak serta tamu hilir mudik berdatangan. Diharapkan setiap warga masyarakat mau berpartisipasi.

Partisipasi masyarakat amat diperlukan dalam melestarikan seni tradisional (Pujiwiyana, 2010: 97). Tetangga kanan kiri siap sambatan, membantu dengan sukarela. Mencari kayu bakar, godhong jati, godhong gedhang, nggodhog teh, pasang bleketepe, tuwuhan, masak dan munjung. Kerja berat yang melibatkan banyak orang. Sementara keluarga dekat diminta menjadi among tamu. Berkumpul, pesta dan nanggap tayub. Bagi masyarakat seni tayub merupakan ritual untuk mendatangkan kemakmuran.

\section{Pertunjukan Seni Langen Tayub}

Masyarakat memahami tayub sebagai aktivitas spiritual. Penari tayub menempati posisi penting dan mendapat pelatihan khusus sebelum mereka pentas. Penggambyong adalah seniwati asal Kabupaten Nganjuk yang bertugas menari dan menyanyi saat penyelenggaraan pentas seni beksa langen tayub (Soetrisno, 2017: 79). Masyarakat Banyumas, Cilacap, Purbalingga dan Kebumen menyebut penggambyong dengan istilah Ronggeng. Kabupaten Banjarnegara dan Wonosobo memberi nama Lengger. Orang Yogyakarta, Sleman, Bantul, Gunungkidul, Kulonprogo mengenal dengan sebutan Ledhek. Kehadirannya diperlukan untuk upacara ritual tradisional.

Di daerah lain pun mengenal kesenian sejenis. Nama Tandhak populer di wilayah Jombang, Mojokerto, Lamongan, Surabaya, Sidoarjo dan Malang. Penggambyong mempunyai sinonim dengan ledhek, ronggeng, lengger dan tandhak. Masing-masing merupakan manivestasi seni spiritual masyarakat tradisional.Kesenian tayub ini digunakan untuk beragam kegiatan masyarakat. Upacara nyadran, bersih desa, sepasaran bayi, pernikahan, tetakan, merti dhusun, merti bumi, slup-slupan rumah, panen, wiwit dan boyongan selalu mengundang penggambyong untuk berjoged. Kehadiran penggambyong demi laku ritual yang dapat menolak bala, bebas dari bencana dan rintangan hidup. Semua slamet wilujeng, tenteram lahir batin. Oleh karena itu penyelenggaraan seni tayub itu harus mengikuti kaidah, norma, pakem, tradisi, adat-istiadat aturan yang baku. Ketentuan ini telah diwariskan secara turun-temurun. Hal ini mengindikasikan adanya usaha pelestarian yang konsekuen dan konsisten.

Begitu pentingnya maka masyarakat mau membiayai pelaksanaan ritual tayuban. Dalam tata cara langen tayub, penggambyong mendapat gelar kehormatan waranggana. Kata waranggana berasal dari bahasa Sansekerta yaitu wara dan anggana. Wara berarti wanita yang mulia, agung dan anggun. Sedangkan anggana mempunyai makna indah, adi luhung dan edi peni. Pertunjukan beksanmasih erat terkait dengan kepercayaan (Salmurgiyanto, 2020: 11). Bagi para petani yang rajin menanam padi di sawah tentu meyakini penggambyong sebagai kekasih Dewi Sri. Kepercayaan Jawa bahwa Dewi Sri merupakan widodari yang mengurusi pangan. Pari bisa tumbuh subur manakala diemong oleh Dewi Sri. Hal ini merupakan bentuk ungkapan religiusitas.

Secara hermeneutik dapat menjelaskan tentang penafsiran terhadap masyarakat kesenian yang dilakukan oleh penafsir dengan menyadari bahwa dirinya sendiri di tengah-tengah sejarah yang menyangkut baik penerimaan maupun penafsiran, cara dia mengerti sebuah teks yang turut dihasilkan tradisi 
(Jan Van Luxemburg, 1986:62-63).Proteksi spiritual memang amat diharapkan. Perlindungan, pengayoman serta perhatian Dewi Sri pada petani menyebabkan pangan berlimpah ruah. Murah sandang, pangan dan papan menjadi cita-cita utama para among tani. Sembada dan sempulur kehidupan itu manakala tersedianya sandang, pangan, papan. Para kadang among tani begitu tinggi harapannya pada Dewi Sri.Kadang tani mengerti cara menghormati Dewi Sri, yaitu dengan nanggap penggambyong. Tiap kali penggambyongnjoged di rumahnya, berarti tanah sawahnya subur. Gerak beksanpenggambyong menjadi pupuk, rabuk dan humus. Alunan suara penggambyong menyebabkan tegalan gembur. Tanduranijo royo-royo memberikan harapan datangnya rejeki yang berlipat ganda (Soetrisno, 2017: 55). Seolah-olah penggambyong penyambung hubungan antara Dewi Sri dengan para tani di sawah. Religiusitas pertanian ini berlangsung di kawasan masyarakat desa.

Misalnya saja tentang mitologi Dewi Sri. Dewi Sri sebagai istri Bathara Wisnu menjelma di Tanah Jawa memang menjadi penyelaras kehidupan. Dalam cerita pewayangan Dewi Sri pernah nitis pada Dewi Citrawati, permaisuri Prabu Harjuna Sasrabahu raja di kraton Mahespati. Kemudian nitis pada diri Dewi Sinta, permaisuri Prabu Rama Wijaya, raja Pancawati. Lantas nitis pada diri Dewi Wara Sembadra, istri Raden Arjuna di Kasatriyan Madukara. Dewi Sri atau Dewi Widowati selalu disebut oleh Prabu Dasamuka di mana saja. Dengan harapan kerajaan Alengka Diraja dan sejahtera.

Dalam sistem kepercayaan masyarakat Jawa ada kepercayaan khusus. Pasangan Dewa Wisnu dan Dewi Sri dianggap pahlawan bagi petani. Penokohan atas dua figur ini kuat mengakar dalam hati petani. Diharapkan segala makhluk halus tak mengganggu. Dhandhang Mangore, Nusa Kambangan dan Pasetran Ganda Mayit menjadi sentra lokasi para mahluk halus. Dengan rapal dan rajah yang dibacakan oleh Dhalang Kandha Buwana, titisan Bathara Wisnu tentu tidak akan sor prebawa atau kalah pamor. Eksistensi dalang menjadi referensi utama dalam bidang spiritual.

Dalang dianggap sebagai orang yang mampu mengusir berbagai malapetaka yang mengganggu kehidupan. Hama wereng, walang sangit, uler, klabang, kalajengking, kala sundep, tikus dan sejenisnya adalah musuh utama bagi petani. Hewan pagebluk ini betul-betul merugikan petani. Cara mengusir hama tanaman ini harus menggunakan aktivitas ritual dan spiritual. Wayang, penggambyong, kethoprak, ludruk, jathilan, kentrung, emprak, dhongkrek, srandhul, ndolalak dan reog merupakan sarana mengusir berbagai hama pertanian. Semua seni tradisional itu disenangi oleh Dewi Sri. Oleh karena itu perlu ditanggap, dengan tujuan untuk mendapatkan barokah.

Masyarakat hendaknya menempuh apresiasi seni sejak dini (Widaryanto, 2007: 36). Nanggap penggambyong berarti rejekinya mbanyu mili, mengalir deras. Sawab dan sawan penggambyong berpengaruh pada doa serta panuwun petani. Petani merasakan harapannya terkabul jika penggambyong mau mendoakan. Doa penggambyong pasti dipenuhi Tuhan. Penggambyong yang mau mendoakan penanggapnya terbukti manjur. Seolah-olah penggambyong adalah perantara atau penghubung antara Tuhan dengan petani. Ekspektasi spiritual ini berlaku secara umum. 
Dari aspek batiniah memang amat erat antara seni dengan spiritual. Sumbaga atau aura spiritual penggambyong terpancar saat tampil di panggung. Tangan bergerak, kaki melangkah dan suara melengking, pada saat itulah penggambyong tampil dengan segala pancaran wibawa. Sejak cikar datang membawa gamelan, para makhluk halus sudah menanti dengan riang gembira. Gamelan digelar bangsa yang tak kasat mripat mulai berdatangan. Mereka berpartisipasi demi kelancaran langen tayub. Petani yang nanggap tayub percaya akan makmur. Panen berlimpah ruah, jauh dari hama. Padi, palawija, pala pendhem, pala gumandhul, pala kesimpar, karang kitri memberi penghasilan.

Sesungguhnya ada pengaruh gejolak ekonomi terhadap perkembangan seni (Soedarsono, 2003: 233). Penonton ramai, untung pasti berlipat ganda. Palen adalah penjual yang menjajakan mainan, plembungan, slathokan, wayang, kitiran dan ragam dolanan anak-anak. Mereka pindah dari tempat satu ke tempat lain. Dimana saja ada tontonan, bakul palen silih berganti berdatangan. Keuntungan yang berlipat ganda cukup menghidupi keluarga. Betapa tidak, anak-anak kecil pasti minta dibelikan mainan. Berapa pun harganya, pasti diminta. Modalnya cuma nangis. Orang tua dan kakek nenek meluluskan permintaan anak kecil. Itulah kepercayaan masyarakat tani. Siklus kehidupan pertanian terkait dengan keselarasan alam raya.

Pentas tayub mendatangkan dampak ekonomi. Sepanjang jalan kanan kiri penuh orang berjualan. Anak-anak berlari-lari, bermain-main dengan teman sebaya. Dengan memakai lampu strongking, teplok, senthir dan cublik dirasa lebih dari cukup. Peradaban desa yang dihuni para petani merupakan kawasan mandiri, produktif dan kreatif. Perlu adanya usaha serius dalam pelestarian seni beksan (Marwanto, 2009: 75). Langen tayub telah memutar roda perekonomian. Ujaring mbok bakul sinambi wara, informasi yang bersambung dari mulut ke mulut, gathok tular, menular dari seseorang ke pihak lain. Tontonan tayub akan segera menyebar ke segala pelosok, dari perkotaan, pedesaan dan pegunungan. Kesenian tradisional yang ditunggu-tunggu oleh masyarakat. Aspek ekonomi ini jelas mendatangkan keuntungan.

\section{HASIL PENELITIAN DAN PEMBAHASAN}

Usaha Pelestarian dengan Pendidikan

Pelatihan dan pendidikan menjadi sarana untuk pelestarian kesenian. Di balik gerak terdapat proses penanaman perilaku peserta didik pada keindahan (Irawati Durban, 2004: 9). Nilai estetis ini perlu diperhatikan dengan menggunakan sebuah padepokan pendidikan.

Unjuk kebolehan memang penting. Gambyongan pasti disaksikan oleh para bidadari dari Suralaya. Dewi Gagar Mayang, Irim-irim, Supraba, Mularsih, Wilutama, Tunjung Biru dan Dewi Sri berkenan hadir. Mereka menyaksikan dengan seksama gerak-gerik penggambyong yang lemah gemulai. Peristiwa penting yang dihadiri oleh rombongan widodari dari Kahyangan Junggring Salaka tanda bahwa para penggambyong yang diwisuda tersebut siaga untuk menjalankan tugas. Laku spiritual dijalankan dengan penuh penghayatan.

Ada kepercayaan di kalangan masyarakat Nganjuk. Sumur Mbah Ageng digunakan untuk mandi. Para penggambyong yang diwisuda diguyur dengan 
siwur atau jebas sebanyak tujuh kali. Air yang dicampur dengan kembang setaman menambah karisma penggambyong (Soetrisno, 2017: 41). Menurut cerita kuna, dulu Dewi Sekartaji Galuh Candra Kirana sempat raup atau membasuh muka di sumur ageng atau sumur gumuling. Khasiat air dari sumber sumur gumuling ini bisa menambah kecantikan dan daya pikat. Penggambyong yang telah mandi di sumur gumuling tampak ayu, menarik hati serta mengesankan. Ditanggung kariernya cemerlang, tanggapan laris manis dan banyak penggemar. Penggambyong tadi pasti menjadi artis terkenal.

Pulau Jawa punya tempat yang bernuansa magis spiritual. Tempat-tempat yang biasa untuk lelaku para penggambyong yaitu Kali Kedhung Ngaton, Grojogan Sedhudha, Telogo Putri, Sendhang Sriningsih, Umbul Cakra, Rawa Pening, Tirta Pengging dan Bengawan Solo. Para penggambyong melakukan siram jamas, sesuci dhiri dan berendam tapa kungkum. Dengan ritual berendam dalam air ini semua energi masuk ke tubuh penggambyong. Ngadi busana dan ngadi saliratambah patut. Suara semakin nyaring dan gerak-gerik beksanan memikat hati.Tapa di Gunung Danaraja agar para penggambyong memperoleh tetesan cantik dari Kanjeng Ratu Kalinyamat. Cerita Babad Tanah Jawi ini diyakini benar oleh masyarakat Jawa.

Tempat-tempat yang magis pun tidak boleh dilupakan. Pasareyan atau makam yang kerap didatangi oleh para waranggana, penggambyong atau pesindhen yaitu Makam Kempul. Dulu Gusti Kanjeng Ratu Pembayun, putri Panembahan Senopati pernah menjadi penggambyong. Tiap hari untuk mbarang atau ngamen. Panembahan Senopati tetap menganggap $\mathrm{Ki}$ Ageng Mangir Wonoboyo sebagai musuh. Ratu Pembayun setelah wafat dimakamkan di Kempul Taji, timur Candi Prambanan.

Ada lagi tempat yang dijadikan peziarahan. Makam Kanjeng Jumat yang berada di Brebek lereng Gunung Wilis itu juga mendukung suksesnya karier waranggana tayub. Kanjeng Jumat mempunyai Aji Jaya Kawijayan. Namanya jimat Prita. Khasiatnya membuat panuwunan atau doa penggambyong dikabulkan. Ketika jimat Prita diwatek atau dipakai gerak dedaunan turut pula mendoakan. Angin sumilir menerjang kembang-kembang berbau wangi. Bersamaan dengan dupa kumelun, maka segala doa yang dipanjatkan akan menembus langit sap tujuh. Kegiatan ini bertujuan untuk mendatangkan aura seni.

Kualitas seni amat menentukan bagi sebuah marketing. Demi menjaga kualitas seni, para penggambyong tayub akan lek-lekan di Dlepih Tirtomoyo Wonogiri. Panembahan Senopati sering mengantar Kanjeng Ratu Pembayun untuk mendapatkan wahyu Budaya. Betul juga, Ratu Pembayun terampil dalam membawakan seni budaya adi luhung. Mereka adalah penjaga folklor kesenian. Dengan penuh penghayatan semua tugas dijalankan. Saat bertugas untuk mbarang ngamen, semua orang terpikat pada Ratu Pembayun yang telah mendapatkan wahyu seni budaya. Putri Pembayun yang kewahyon ini memang mumpuni. Dalam tradisi sejarah Jawa cerita tersebut memang cukup populer.

\section{Legitimasi Sosial Budaya}

Wisuda bagi waranggana tayub atau penggambyong digunakan sebagai sarana legitimasi sosial dan budaya. Penggambyong tenar, mahal, banyak penggemar, laris dan selalu ditunggu-tunggu penampilannya menjadi impian para 
penari gambyong(Soetrisno, 2017: 42). Nyi Sumiati dari Ngawen, Tempursari, Ngluyu, idola pada pendhemen tayub. Suaranya nyaring cumlereng memenuhi angkasa raya. Kepada siapa saja ramah tamah, amat menghargai dan menabur senyum menawan.

Terdapat beberapa busana yang perlu diperhatikan. Dandanannya serba pantes, sanggul, kemben, selendhang, stagen, cindhe, nyamping, cundhuk mentul, susuk, gelang, kalung, ali-ali, suweng, dikenakan selaras dengan postur badan. Isi beksanan adalah elemen konsepsi yang masuk kategori nilai internal beksan (Iyus Rusliana, 2001: 26).Waranggana tayub yang juga terkenal bernama Nyi Sumiatun.Di daerah Nganjuk Sumiatun merupakan penggambyong pujaan.

Tunjuk kebolehan bagi penggambyong terkait dengan aspek promosi. Gembyangan Waranggana adalah upacara wisuda di padhepokan Langen Tayub. Pendhopo seni untuk wisudan penggambyong terletak di dusun Ngrajek, Desa Sambirejo Kecamatan Tanjunganom Kabupaten Nganjuk. Pelaksanaan tiap hari Jumat Pahing bulan Besar. Piranti yang tersedia di Pundhen Eyang Ageng yaitu genthong, kembang setaman, sampur, dupa, gamelan dan toya suci. Di daerah ini memang terdapat tuk, sumber air, umbul, belik yang mengalir ajeg dan teratur. Para petani merasa beruntung dengan adanya ritual kesuburan.

Keyakinan terhadap alam pedanyangan amat kental. Pimpinan makhluk halus di sekitar gunung Kendheng, Gunung Wilis, Gunung Pandhan dan Gunung Lawu menyukai sepuluh gendhing yang dipakai gembyangan penggambyong. Ketika gendhing tadi diiringi suara gamelan seketika para dhanyang sama mbeksa, njoged dan menari riang gembira. Oleh karena itu kesepuluh gendhing sakral ini menjadi sajian wajib saat upacara sakral gembyangan waranggana. Sajian gendhing ritual ini sesuai dengan tuntunan pakem.

Pengrawit dapat diartikan sebagai orang yang bertugas memainkan gending atau notasi dasar lagu sehingga menghasilkan karya musik yang indah (Bram Palgunadi, 2002: 28). Wisuda waranggana menjadi sarana rekonsiliasi antara jagad lahir dengan jagad batin. Penggambyong yang diwisuda diberi cundhuk mentul yang melambangkan sudah resmi menjadi waranggana. Kemudian disuruh memegang godhong waru, yang melambangkan katresnan sejati.

Siraman air dari grojogan Sedhudha agar kalis ing sambekala. Upacara sakral ini berlangsung dan wajib dilakukan sebelum waranggana, penggambyong, tandak, pesindhen atau ronggeng tampil di pasaran. Peranan seniman merupkan unsur penting dalam pembinan seni (Popo Iskandar, 2000: 9).Popularitas seorang penggambyong ditentukan oleh keterampilan dan kepintaran dalam sasana budaya. Penggambyong yang misuwur, kondhang, kawentar, kasusra, tenar dan ternama mesti diperoleh dengan cara ngelmu dan laku. Ketrampilan dan pengalaman dengan yakin berguru kepada penggambyong senior dan para sesepuh. Lelaku dengan menjalankan lara lapa tapa brata.Pelestarian dan pengembangan seni tradisi perlu mengetahui adanya transformasi seni dalam budaya (Sumaryanto, 2007: 113). Demikian hubungan antara pentas tayub dengan kemakmuran di kalangan petani. 


\section{PENUTUP}

Berdasarkan uraian di atas dapat dikatakan bahwa masyarakat Nganjuk yang berprofesi sebagai petani di pedesaan pada saat panen kerap mementaskan seni langen tayub. Penggambyong adalah seniwati yang bertugas menari dan menyanyi pada saat pagelaran seni langen tayub.

Tata cara ngelmu lakupenggambyong dilakukan dengan laku spiritual.Petani yang mau menanggap seni tayub akan terbebas dari segala macam cobaan hama. Oleh karena itu masyarakat menganggap bahwa pentas seni tayub menjadi simbol untuk mengharapkan datangnya kemakmuran.

Pentas seni tayub memang mengandung nilai ajaran moral yang tinggi. Pada masa depan mudah-mudahan seni tayub tetap lestari dan dapat memperkokoh jatidiri bangsa.

\section{DAFTAR PUSTAKA}

Bram Palgunadi, 2002. Serat Kandha Karawitan Jawi: Mengenal Seni Karawitan Jawa. Bandung: ITB

Irawati Durban, 2004. Teknik Gerak Beksan dan Beksan Dasar Sunda. Bandung: Purbibeksan

Iyus Rusliana, 2001. Khasanah Beksan Wayang. Bandung:STSI Press

Luxemburg, Van dkk, 1986. Pengantar Ilmu Sastra. Terjemahan Dick Hartoko. Jakarta: Gramedia.

Marwanto, 2009. Seni Joged Gagrak Mataram. Yogyakarta: Paradigma

Peter Brook, 2002. Percikan Pemikiran tentang Teater, Film dan Opera. Yogyakarta: Arti

Popo Iskandar, 2000. Alam Pikiran Seniman. Yogyakarta: YAI

Pujiwiyana, 2010. Pembinaan Paguyuban Seni Tradisional. Yogyakarta: Almatera

Salmurgiyanto, 2002. Kritik Beksan Bekal dan Kemampuan Dasar. Jakarta: MSPI

Soedarsono, 2003. Seni Pertunjukan dari Perspektif Politik, Sosial dan Ekonomi. Yogyakarta: Gama Press

Sumaryono, 2007. Jejak dan problematika Seni Pertunjukan Kita. Yogyakarta: Prasista

Soetrisno, 2017. Ensiklopedi Kabupaten Nganjuk. Yogyakarta: Bangun Bangsa.

Widaryanto, 2007. Menuju Representasi Dunia Dalam. Bandung: Kelir. 